\title{
Investigation of a Digital Hydraulic Valve Operated by Servo Motors
}

\author{
Adem Fatih Ozalp \\ Department of Mechanical Engineering \\ Karabuk University \\ Karabuk, Turkey \\ ademfatihozalp@karabuk.edu.tr \\ Celalettin Cetinkaya \\ Department of Mechanical Engineering \\ Karabuk University \\ Karabuk, Turkey \\ c.cetinkaya06@hotmail.com
}

\author{
Refik Polat \\ Department of Mechanical Engineering \\ Karabuk University \\ Karabuk, Turkey \\ refikpolat@karabuk.edu.tr \\ Muhammet Huseyin Cetin \\ Department of Mechanical Engineering \\ Konya Technical University \\ Konya, Turkey \\ mhcetin@ktun.edu.tr
}

\begin{abstract}
This paper describes a new type of digital hydraulic valve run by two servo motors. Digital hydraulics is a cuttingedge technology, which saves more exhausted energy than conventional hydraulic valves. It includes conventional valves, but its working principle is different. Similar or different size valves constitute a digital hydraulic valve assembly. When the assigned valves are opened, a certain amount of flow is obtained from the output of the valve assembly. To control a digital hydraulic valve, Pulse Number Modulation (PNM) Control technique is used for equal valve flow rates, while Pulse Code Modulation (PCM) is used for different valve flow rates. Valves are exerted by independently launched electric coils. Previous studies used controller board and external power booster circuits for coils. In this study, a new type of digital hydraulic valve is designed, manufactured, and tested with the PNM method. The studied valve body has two different valve groups. Every group includes 16 equal valves and 1 camshaft rotated by 1 servo motor. The servo motors are controlled by a PLC. The calculated performance index is found to be $5.1 \mathrm{~ms}$ which is similar to the results of previous studies. The experimental results showed that the cam and servo motor controlled digital hydraulics is applicable to variable speed control hydraulic systems.
\end{abstract}

Keywords-hydraulic control; digital hydraulics; position control; valve design

\section{INTRODUCTION}

Hydraulic cylinders and hydraulic motors are used for lifting and turning heavy loads. Elevators, presses, excavators, buckets, and dams are common areas of use. When precise position control is required for lifting heavy or light loads, and the lifting system has limited space, hydraulic systems are applied instead of electric actuators. Proportional and servo valves are used for precise position control with a hydraulic cylinder. However, these high cost valves can easily break down due to contamination in the oil. This paper presents a hydraulic valve which can be used in precision position control applications, can work in the performance of servo and proportional valves, is resistant to oil contamination, and saves more energy than the conventional valves. The proposed valve is tested for speed and position control with a hydraulic cylinder.

Pressurized flow valves have been highly investigated in order to increase the performance of a system. Pressure and flow rate change during the operation greatly affect the behavior of the system [1, 2]. On-off directional valves, proportional valves, servo valves are often used for a single hydraulic cylinder or a single motor. Authors in [3] used two independent proportional valves each for one port of a hydraulic cylinder, reducing the energy losses by $15 \%$. Authors in [4] increased the controllability of the system by running the inlet and outlet ports of a hydraulic cylinder by 5 separate proportional valves. In addition, the efficiency of the system has increased. The lines to and from the cylinder were controlled by 4 proportional valves. Another valve saves the potential load energy that the cylinder lifts and increases the system efficiency by connecting the return line of the hydraulic cylinder to the system. Authors in [5] proved that parallelconnected on-off valves can be used as servo valves in the digital hydraulic method. In this method, the hydraulic system using water as fluid is operated with valves located in parallel. The valves have different flow rates and are controlled by the binary coding method. The data obtained in the experiment showed that velocity and position graphs are similar to the servo valve actuated system. However, it was found that the pressure shocks in the system are high.

Proportional and servo valves alone are generally used with a hydraulic cylinder, and a spool of the valve regulates the amount of flow through the valve. However, in digital hydraulics, the on-off valves just open and close and are more than one. The flow rate of each valve is a small amount of the total flow of the system. The flow rate of each valve may be 
different or equal to the others'. If the valve flow rate is desired to be the same, valves with a very small flow rate are required in order to increase their accuracy, so the number of valves increases. If the valve flow rate is selected in multiples of 2 by the binary coding method, four valves will be sufficient instead of sixteen equal valves. The sensitivity will be $1 / 16$ times. The Fibonacci (1:1:2:3:5) method is similar to the binary coding method and the flow rates are chosen using different coefficients. In this way, when the valve flow rate is selected as a coefficient of some numbers, pressure shocks occur during the opening and closing of the valves at system pressure. These pressure shocks cause undesirable results in system control, hydraulic system parts and make it difficult for the system to operate linearly [6].

Authors in [7] evaluated the hydraulic systems required in the ITER fusion reactor. They stated that the hydraulic system to be used in the reactor would take a narrow space, work in high radiation, and should carry high reliability and high sensitivity. They mentioned that the digital hydraulic method would be suitable for this because the system is capable of tolerating errors. When they compared the servo hydraulic system to the digital hydraulic system, they obtained similar position tracking results. However, the digital hydraulic system made oscillation movements when servo systems gave more linear results at low speeds. They stated that using more on-off valves should be used to solve the pressure fluctuation causing oscillations. When separate valves are placed differentially in the A and B pressure and tank lines to the system, all four flow lines can be controlled independently. Controller systems using 2-5 independent proportional valves instead of only one proportional valve are called programmable, multifunctional, independent line, and distributed line. Since the valve system is used differentially, these systems are energy efficient, and their losses are minimized. When a single proportional valve is used, the valve spool regulates the flow to the pressure line and tank line equally [8-10]. Digital hydraulic control method is superior compared to proportional and servo systems. In the case of a digital hydraulic system, when a valve fails, the system is capable of continuing operation.

Digital hydraulics systems are cheaper compared to proportional and servo systems and can cost even less if they are mass manufactured. They have the advantages of not requiring spool feedback as the proportional or servo valves [11-13]. The model-based controller system is used to control the digital hydraulic system. The controller operates based on a steady-state model and does not require dynamic modeling, so it does not make many calculations during the operation of the system. In this method, the control technique is based on reducing the previously calculated estimates in an optimal way by using the cost function method. During the operation of the system, the best reference command is determined by comparing the measurements taken from the position, pressure, and flow sensors with the estimated data to be operated with minimum energy, and the system is controlled according to [14-15]. Authors in [16, 17] conducted the experiments of a hydraulic system powered by a fixed displacement pump, working with a four-zone secondary controller and variable displacement hydraulic motor. In this system, it is not possible to produce a hydraulic cylinder with a variable piston similar to its variable displacement motor in today's conditions. Instead, authors in [16] used telescopic independent pistons and cylinders. The cylinder is connected to a boom arm and has loads of $200 \mathrm{~kg}, 150 \mathrm{~kg}, 100 \mathrm{~kg}$, and $50 \mathrm{~kg}$ on the arm. The system shows $60 \%$ reduction in energy losses compared to systems operated by proportional and servo valves. This system is well controlled at high speeds but faces problems at low speeds. In contrast to the previous systems, a safety valve and a second flow sensor outside the pump line are installed to measure energy efficiency. It was found that the energy saving of this experimental system is increased by reducing the energy loss in the pressurized flow to the tank. Authors in [18] operated a three-part hydraulic cylinder with 3 digital hydraulic control units including 8 on-off valves each. This system is operated by digital hydraulics and its energy loss is reduced by $66 \%$. In the experimental system, the hydraulic cylinder is connected to a single degree of freedom lever, and the lever is required to keep fixed permanently.

Authors in [19] tested a lever mechanism with an electronic load sensing pressure system, a distributed digital hydraulic control unit, and a pressurized tank line. The system had a hydraulic accumulator connected to the tank line. The flow from the system to the tank was pressurized by a relief valve. The studied system's energy losses decreased by $53 \%$ to $71 \%$ compared to the proportional valve systems. Authors in [20] examined a system of miniature valves to lift a load of $50 \mathrm{~kg}$. Their system worked successfully for $15 \mathrm{~mm}, 50 \mathrm{~mm}$, and $100 \mathrm{~mm}$ position displacement. The coefficient found by dividing the derivative of the position error over time by velocity was determined as a success. Their obtained coefficient was $1.7 \mathrm{~ms}$ which is much better than the $5.3 \mathrm{~ms}$ found in [21]. In the newly developed digital hydraulic method, instead of a servo valve, simple on-off poppet valves with equal fluid flow rate are used. The total number of the poppet valves is at least 2 . In order to reduce the total number of poppet valves, valves with different flow rates are selected in multiples of two (binary coding). Thus, instead of 16 openclose valves, the same process can be applied with 4 on-off valves. In the digital hydraulic control method, when one of the valves breaks down, the system continues to operate, and the operation of the system is not disrupted at all [19].

Controlling four or more valves at the same time with binary coding in PCM method causes undesired pressure fluctuations in the system. Other PNM methods use equal flow rate commercial valves that require more valves and more space in digital valve assembly. To solve that, custom made miniature valves are produced. This type of assembly is smaller compared to the commercially used valve assembly. Either commercial or custom-made valves require high performance electronic control cards and additional valves are added to the system to show a damping effect. Therefore, the complexity of the system increases [19, 21-24].

The above mentioned digital hydraulic valves involve independent control components for each small valve flow rate and that makes it even more complicated. The proposed valve has one camshaft and a servo motor for 16 same flow rate valves, which is better coordinated to control the valves. 


\section{CONCTROL PRINCIPLE}

The steady state model and the cost function presented in [5] are used to control the suggested valve. For the extending movement of the steady state, the equations of the system are:

$$
\begin{gathered}
Q_{\mathrm{N}, \mathrm{P}}=\sum_{\mathrm{i}=1}^{\mathrm{n}_{\mathrm{P}}} \mathrm{u}_{\mathrm{Pi}} Q_{\mathrm{N}, \mathrm{Pi}} \\
Q_{\mathrm{P}}=\boldsymbol{Q}_{\mathrm{N}, \mathrm{P}}\left(u_{\mathrm{P}}\right) \sqrt{P_{\mathrm{S}}-P_{\mathrm{A}}}=A_{\mathrm{A}} \\
Q_{\mathrm{T}}=\boldsymbol{Q}_{\mathrm{N}, \mathbf{T}}\left(u_{\mathrm{T}}\right) \sqrt{P_{\mathrm{B}}}=A_{\mathrm{B}} \\
F=A_{\mathrm{A}} P_{\mathrm{A}}-A_{\mathrm{B}} P_{\mathrm{B}} \\
\mathrm{z}=[4) \\
\left.\boldsymbol{Q}_{\mathrm{N}, \mathrm{P}}\left(u_{\mathrm{P}}\right)\right] /\left[\boldsymbol{Q}_{\mathrm{N}, \mathrm{T}}\left(u_{\mathrm{T}}\right)\right] \\
\gamma=A_{\mathrm{A}} / A_{\mathrm{B}} \quad(6) \\
P_{A}=\frac{z^{2} P_{\mathrm{S}}+\gamma^{2} F / A_{\mathrm{B}}}{z^{2}+\gamma^{3}} \quad(7) \\
P_{B}=\frac{\gamma z^{2} P_{S}-z^{2} F / A_{B}}{z^{2}+\gamma^{3}}(8) \\
v=\frac{\boldsymbol{Q}_{\mathrm{N}, \mathrm{P}}\left(u_{\mathrm{P}}\right)}{A_{\mathrm{B}}} \sqrt{\frac{\gamma \mathrm{P}_{\mathrm{S}}-F / \mathrm{A}_{\mathrm{B}}}{\mathrm{z}^{2}+\gamma^{3}}} \\
W=Q_{\mathrm{P}} \cdot P_{\mathrm{S}} \quad(10)
\end{gathered}
$$

For the retracting movement of the steady state, the equations of the system are:

$$
\begin{gathered}
P_{A}=\frac{\gamma^{2} P_{\mathrm{S}}+\gamma^{2} F / A_{\mathrm{B}}}{z^{-2}+\gamma^{3}} \\
P_{B}=\frac{\gamma^{3} P_{\mathrm{S}}-z^{-2} F / A_{\mathrm{B}}}{z^{-2}+\gamma^{3}} \\
v=-\frac{Q_{\mathrm{N}, \mathrm{T}}\left(u_{\mathrm{T}}\right)}{A_{\mathrm{B}}} \sqrt{\frac{P_{\mathrm{S}}+F / A_{\mathrm{B}}}{z^{-2}+\gamma^{3}}}
\end{gathered}
$$

where $\boldsymbol{Q}_{\mathbf{N}, \mathbf{P}}\left(\mathrm{u}_{\mathrm{P}}\right)$ and $\boldsymbol{Q}_{\mathrm{N}, \mathbf{T}}\left(\mathrm{u}_{\mathrm{T}}\right)$ are the nominal flow coefficients of the tank side and the pressure side that change with $u_{P}$ and $u_{T}$ which are the element vectors of $\boldsymbol{Q}_{\mathbf{N}, \mathbf{P}}$ and $\boldsymbol{Q}_{\mathbf{N}, \mathbf{T}} . F$ is the force applied by the cylinder, $P_{S}$ is the supply pressure, $P_{A}$ is the piston side pressure of the hydraulic cylinder, $P_{B}$ is the rode side pressure of the hydraulic cylinder, $W$ is system energy and $v$ is the hydraulic cylinder velocity.

Every poppet valve has an equal flow rate. Also, the elements of vectors of $Q_{\mathrm{N}, \mathrm{P}}$ and $Q_{\mathrm{N}, \mathrm{T}}$ consist of the flow rates of these valves. The system is controlled with the steady state equations and the cost function. The least error control input calculated from the cost function is applied to the servo motors. This function can be written as:

$$
\begin{gathered}
\mathrm{J}(\mathrm{k})=\left[v_{\mathrm{r}}(k)-\hat{v}(k)\right]^{2}+K_{\mathrm{pd}}\left[p_{\mathrm{dr}}(k)-\hat{p}_{\mathrm{d}}(k)\right]^{2}+ \\
K_{1}\left[\hat{p}_{\mathrm{A}}(k-1)-\hat{p}_{\mathrm{A}}(k)\right]^{2}+K_{2}\left[\hat{p}_{\mathrm{B}}(k-1)-\hat{p}_{\mathrm{B}}(k)\right]^{2}
\end{gathered}
$$

where $J(k)$ represents the calculated error for the given combination of input, $v_{r}$ is the reference velocity, "^" circumflex is used to represent the calculated values of the below symbol, $p_{\mathrm{dr}}$ represents the downstream reference pressure, $K_{\mathrm{pd}}$ is the weight of downstream pressure error, and $K_{1}$ and $K_{2}$ are the weights of pressure variation for the A and $\mathrm{B}$ sides of the cylinder.

The least error combination shows us the best control switch to achieve less error output. This combination has error vectors that correspond to the vector of $Q_{\mathrm{N}, \mathrm{P}}\left(u_{P}\right)$ and $Q_{\mathrm{N}, \mathrm{T}}\left(u_{T}\right)$ in the same row and column. Thus, less calculated error for the given reference value is applied to the system. Hydraulic systems are sensitive to disturbance and a closedloop controller is efficient to obtain better results [26]. A closed-loop controller is used which can be written as:

$$
v_{\mathrm{rc}}=v_{\mathrm{r}}+K_{\mathrm{P}}\left(y_{r}-y\right)
$$

where $v_{\mathrm{rc}}$ is closed-loop velocity reference, $K_{\mathrm{P}}$ is closed-loop gain, $y_{\mathrm{r}}$ is position reference, and $y$ is the actual position.

A closed-loop controller is used to decrease velocity error (Figure 3). The studied valve is not able to change the direction of the piston, therefore a commercial directional valve is added to the system as shown in Figures 1, 4. The direction signal is shown as $u_{\text {dir }}$ in Figure 3.

\section{Design of THE VALVE}

The studied hydraulic valve has two camshafts, and each one is driven by 1 servo motor. Each camshaft has 16 cams and is used to actuate the valve spools instead of 16 different coils independent of each other. Its rode and piston ports are connected to a commercial 4-way valve to channel the pressurized flow to the pump and tank ports of the used digital hydraulic valve. The studied digital valve has 2 groups of valves. Each group includes 16 equal rate poppet valves and 1 servo motor to exert the spool of the poppets. The studied valve cannot use the binary coding method because the camshaft is able to open the valves one after another while the binary coded method needs to open different flow rate valves independently. For example, the PCM method might run 4 valves, and these are placed as $1 \mathrm{x}, 2 \mathrm{x}, 4 \mathrm{x}$, and $8 \mathrm{x}$ flow rate valves in a line. It will open $1 \mathrm{x}, 2 \mathrm{x}, 4 \mathrm{x}$, and $8 \mathrm{x}$ flow rate valves to have $15 \mathrm{x}$ flow rate or will open $1 \mathrm{x}$ and $8 \mathrm{x}$ flow rate valves to have $9 x$ flow rate. However, the used camshaft will open 16 pieces of $1 \mathrm{x}$ flow rate valves respectively to supply the $16 \mathrm{x}$ flow rate to the system, and the studied valve cannot be used for binary coding method. In addition, for binary coding method, a hydraulic system has a lot of pressure fluctuations while different flow rate poppets are opened. Instead, the studied valve will open the equal flow rate poppets successively by the servo motor with camshaft and the pressure shocks which are produced with the opening and closing of different flow rate valves will be decreased. Thus, pressure shocks that reduce the life and operating accuracy of the system will be prevented.

Two servo motors through camshafts exert the poppet spools in the valve group one by one and each camshaft has 16 different angled cams mounted. As shown in Figure 2, each cam makes an angle of $11,25^{\circ}$ with the next cam. So, for every $11,25^{\circ}$ turn of the camshaft, one poppet in the valve group opens. The valve poppet is pressed down by a running cam lobe and is lifted by spring force. 


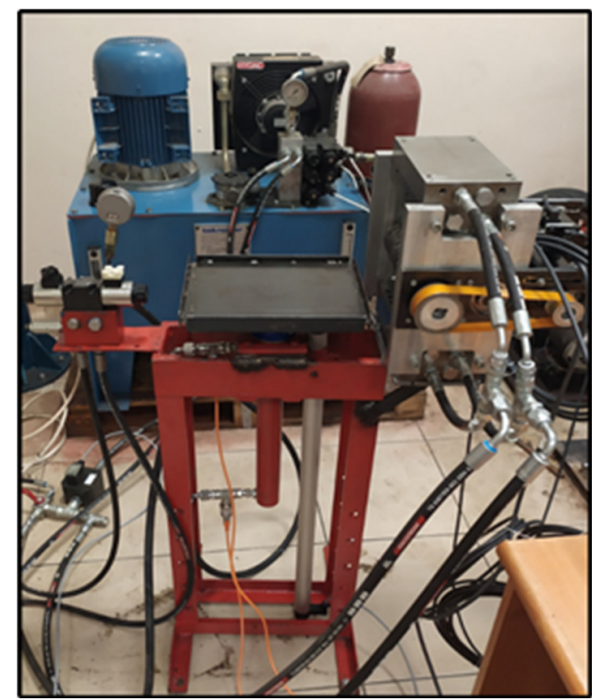

Fig. 1. Test setup.

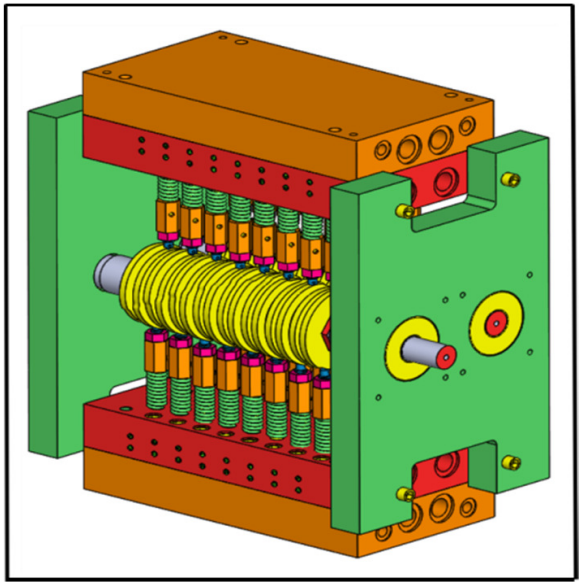

Fig. 2. The valve assembly.
In Figure 2, each camshaft faces two identical valve bodies, below and above. The left sides of the upper and lower body are for the pressure line and the right sides are for the tank line. Each valve body has 2 plates and spools fitted into them. The red color valve plate houses the higher pressurized line, and the orange color plate houses the lower pressurized line. Plates are connected to each other with bolts. Also, two plates hold up each valve body, camshafts, and servo motors from the sides with bolts. To minimize the valve, two opposite valve bodies are used.

\section{TEST SETUP}

The test setup is shown in Figure 1. Loads are placed on the plate, which is attached to the vertical cylinder rode end. Steel frame houses the manufactured valve on the right side and a directional valve on the left side. The vertical hydraulic cylinder is set in the middle of the steel frame. Pressure transducers are connected to the hydraulic cylinder end ports and a linear position sensor is attached to the hydraulic cylinder rode end. A hydraulic pressure supply unit is connected to the valve with hydraulic hoses. The schematic of the hydraulic circuit is shown in Figure 4 . The studied valve body $(8,9)$ and an on-off valve (10) are attached side by side on a frame. A double-acting hydraulic cylinder $(\varnothing 40 \mathrm{~mm} / \varnothing 25 \mathrm{~mm} \times 400$ $\mathrm{mm}$ ) is placed in the center of the frame to lift up loads. Its ports are from the pump and tank ports of the studied valve manifold. Hydraulic hoses are used to connect valves, cylinder, and hydraulic supply to each other. A separate hydraulic supply unit includes a $5.5 \mathrm{~kW}$ electric motor and a $32.51 \mathrm{t} / \mathrm{min}$ fixed displacement pump (1) is used. Servo motors are run by an OMRON PLC unit. Measurements are taken by the same PLC unit. Two pressure transducers (6) are added to the rod pressure line and piston pressure line of the hydraulic cylinder (11) to measure the pressure of the cylinder chambers. To see the flow rate of the pump, a flowmeter (4) is used. Hydraulic cylinder displacement is measured with a linear position sensor (7). Tank (12), check valves (2), relief valve (3), and mechanic pressure gauge (5) are the other system components.

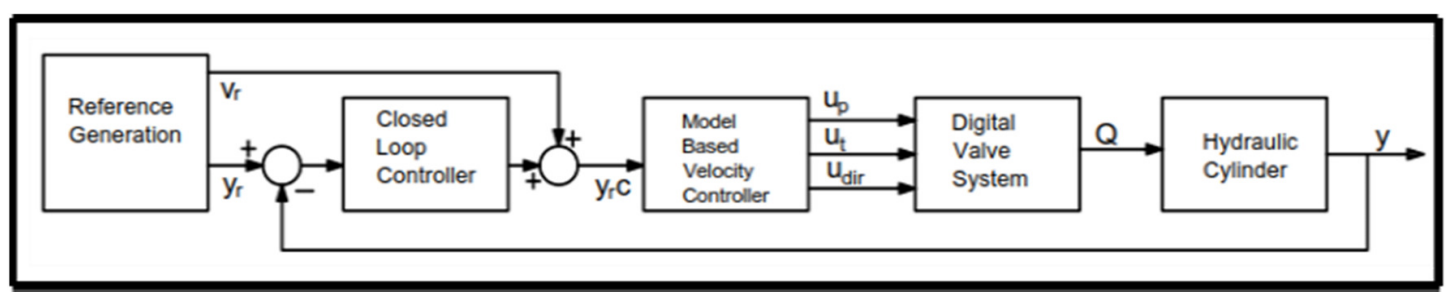

Fig. 3. Block diagram of the closed loop control system.

\section{EXPERIMENTAL RESULTS}

Fifth-order polynomial is used for reference generation. Three different trajectories are chosen, namely $25 \mathrm{~mm}, 50 \mathrm{~mm}$, and $100 \mathrm{~mm}$ back and forth displacement with $2 \mathrm{~s}$ movement time. Each trajectory is performed 4 times and Integral of Square Error (ISE) and maximum position error measurements are compared to see the performance of the system as shown in Table I. After several tests to acquire better cost function parameters $K_{\mathrm{pd}}, K_{1}$, and $K_{2}$, they were found to be $5 \times 10^{-16}$. Nominal flow coefficients $\boldsymbol{Q}_{\mathrm{N}, \mathrm{P} 1}$ and $\boldsymbol{Q}_{\mathrm{N}, \mathrm{T} 1}$ are $1 \times 10^{-8} \mathrm{~m}^{3} /(\mathrm{s} \sqrt{\mathrm{Pa}})$ and $0.9 \times 10^{-8} \mathrm{~m}^{3} /(\mathrm{s} \sqrt{ } \mathrm{Pa})$ respectively. Replaceable orifice cavity is designed on the valve manifold and the flow rate of the valve can be changed by using different diameter bores inside the orifices. However, it is hard to find the desired diameter commercial orifices, so commercial setscrews are drilled and used for the required orifices. It is highly difficult to drill the desired bore below $\varnothing 1 \mathrm{~mm}$ diameter in high strength commercial setscrews. Closed-loop gain is $K_{\mathrm{P}}=35 / \mathrm{s}$ and the used load mass is $50 \mathrm{~kg}$. Output data are filtered with a low-pass filter. For each position tracking experiment, position, position error, velocity, cylinder port pressures, and states of valve 
openings are measured. Figure 5 depicts that $25 \mathrm{~mm}$ position error is bigger than in longer distance trajectories. Both pressure outputs oscillate at maximum speed peak point. Maximum position error is $0.29 \mathrm{~mm}$ at the speed stop point on back forward movement.

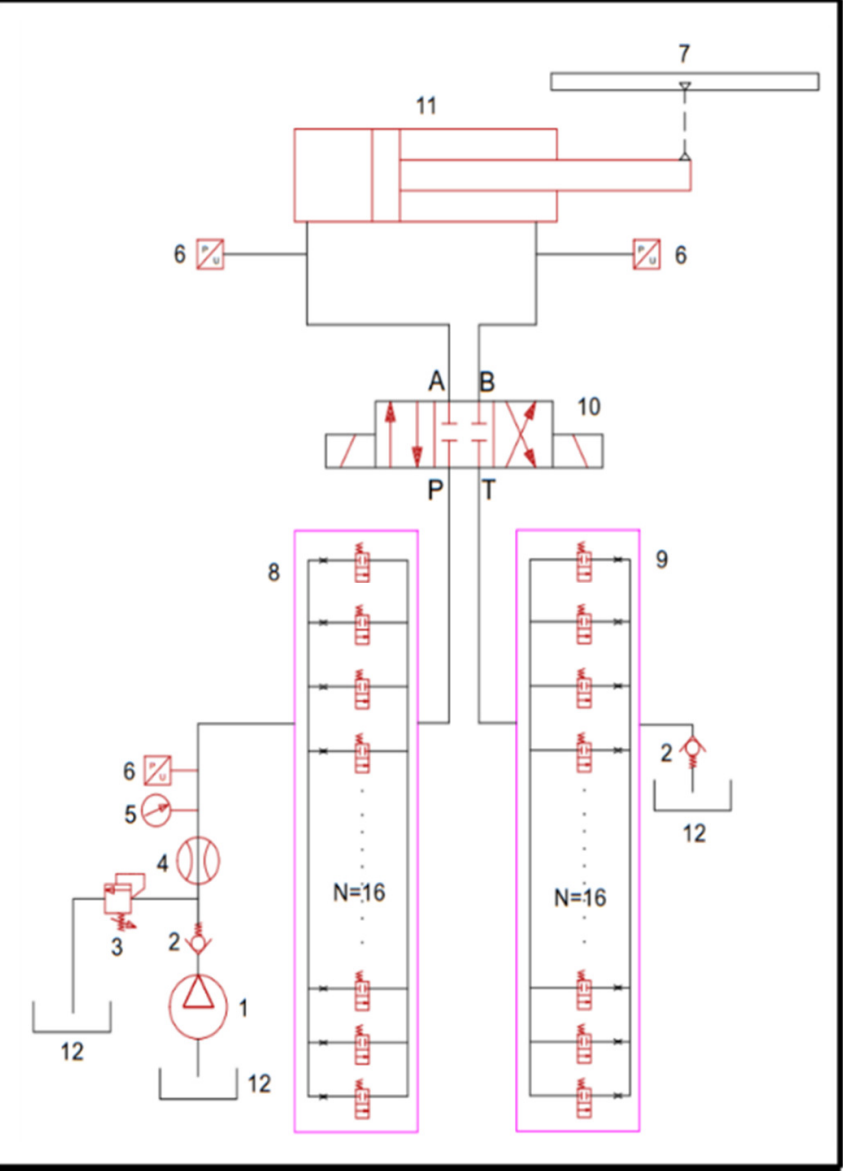

Fig. 4. Hydraulic circuit diagram.

Figure 6 presents the $50 \mathrm{~mm}$ position tracking. The position error is better than the $25 \mathrm{~mm}$ error. There are some pressure fluctuations at extending movement. Retracting movement makes more valve openings than the $25 \mathrm{~mm}$ retracting movement. To decrease cavitation, the $\mathrm{T}$ port flow rate is smaller than the $\mathrm{P}$ port flow rate. Due to the area difference between the rod and piston side, more valve openings occur with a larger speed. Figure 7 shows the pressure fluctuations with both extending and retracting movement of $100 \mathrm{~mm}$ displacement results. These fluctuations happen when it is getting closer around maximum speed peak point. Moreover, the valve opening number increases with speed. Besides, the best maximum position error by speed is $0.51 \mathrm{~mm}$. Previous studies compared their experiments with a performance index method calculated by dividing maximum position error by speed.
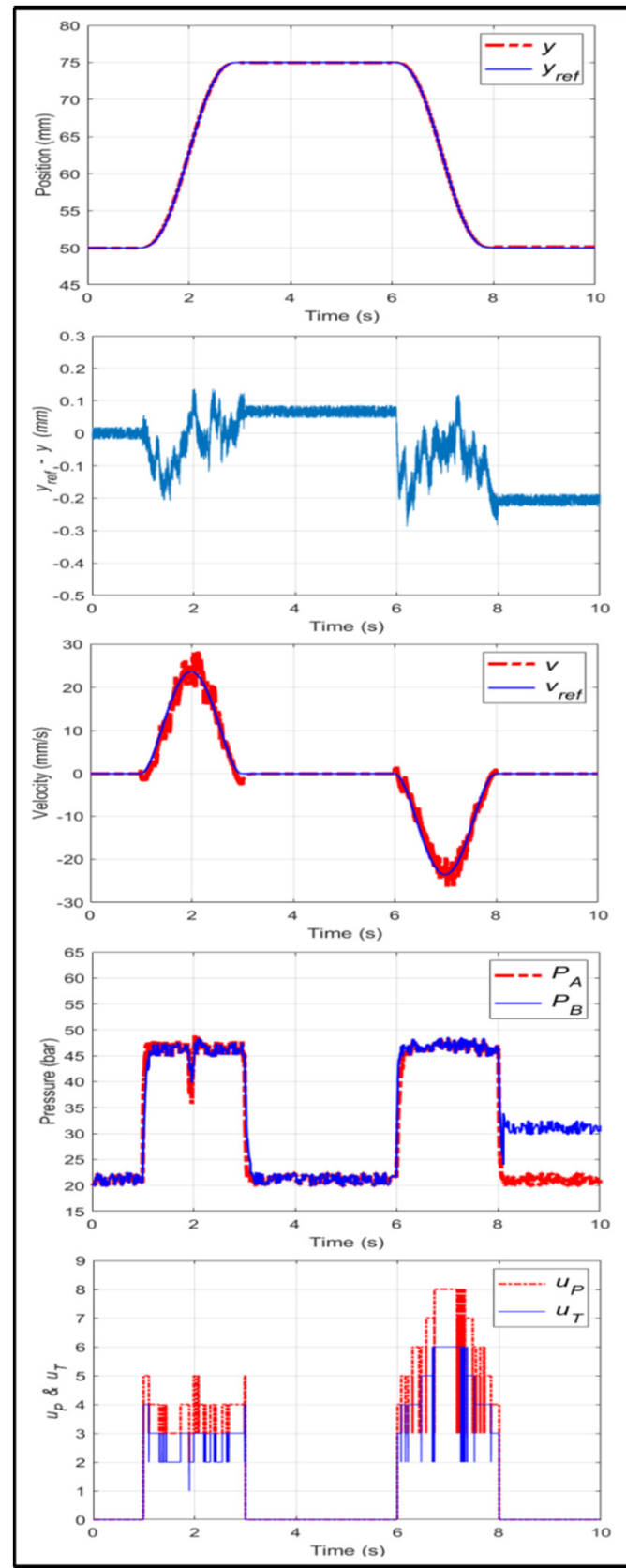

Fig. 5. $25 \mathrm{~mm}$ displacement tracking results.

TABLE I. VALUES OF ISE AND MAXIMUM ERROR FOR POSITION

\begin{tabular}{|c|c|c|}
\hline Trajectory & ISE $\left.\mathbf{( m m}^{2} / \mathbf{s}\right)$ & $\boldsymbol{\Delta x} \mathbf{( m m )}$ \\
\hline $25 \mathrm{~mm}$ & 0.14 & 0.29 \\
\hline $50 \mathrm{~mm}$ & 0.19 & 0.38 \\
\hline $100 \mathrm{~mm}$ & 0.26 & 0.51 \\
\hline
\end{tabular}

\section{CONCLUSION}

In this study, a cam operated digital hydraulic valve is designed, manufactured, tested, and discussed. It is proven to be applicable to solenoid operated digital hydraulic valves, proportional, and servo operated valves. 

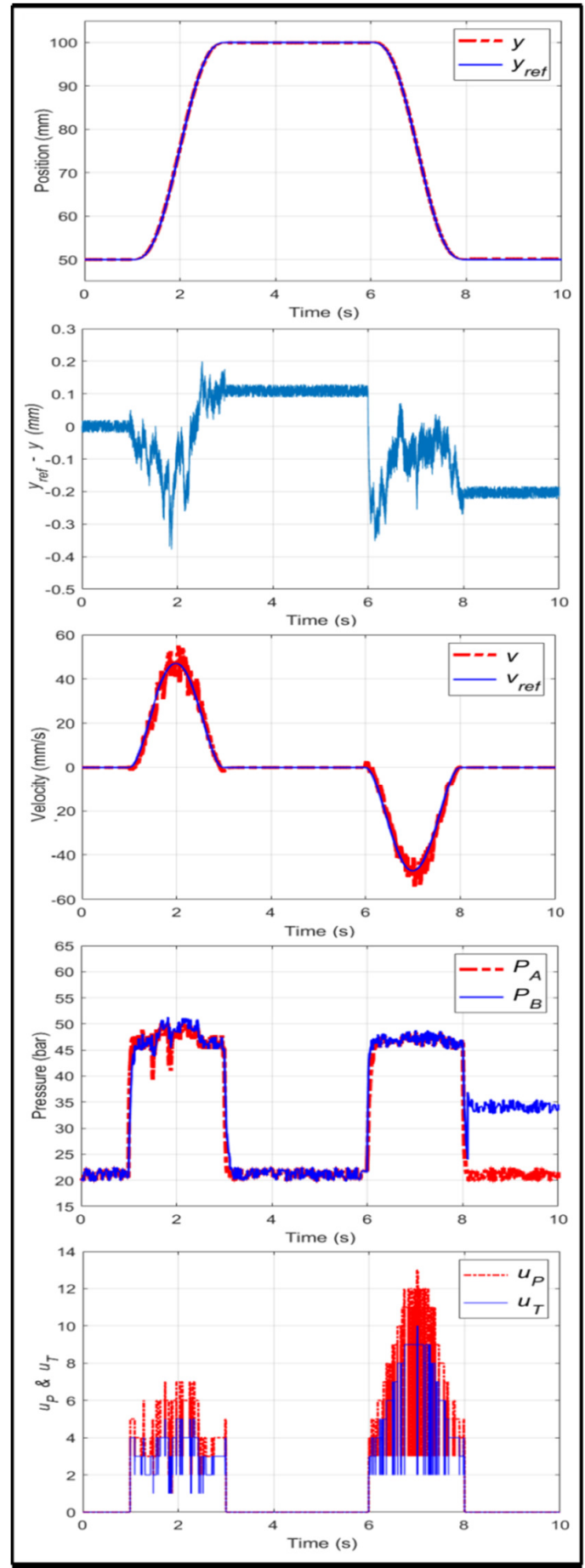

Fig. $6.50 \mathrm{~mm}$ displacement tracking results.

The results show promising values: the $100 \mathrm{~mm}$ trajectory performance index is $5.1 \mathrm{~ms}$, which is similar to the value of $5.3 \mathrm{~ms}$ found in [21]. On the other hand, the $25 \mathrm{~mm}$ trajectory position error is not as good as the $100 \mathrm{~mm}$ trajectory response because valve flow rates are chosen with a wide range which affects the speed and the position error. However, the valve is self-designed and manufactured allowing orifice change, and hence proper flow rates can be applied to the desired systems.

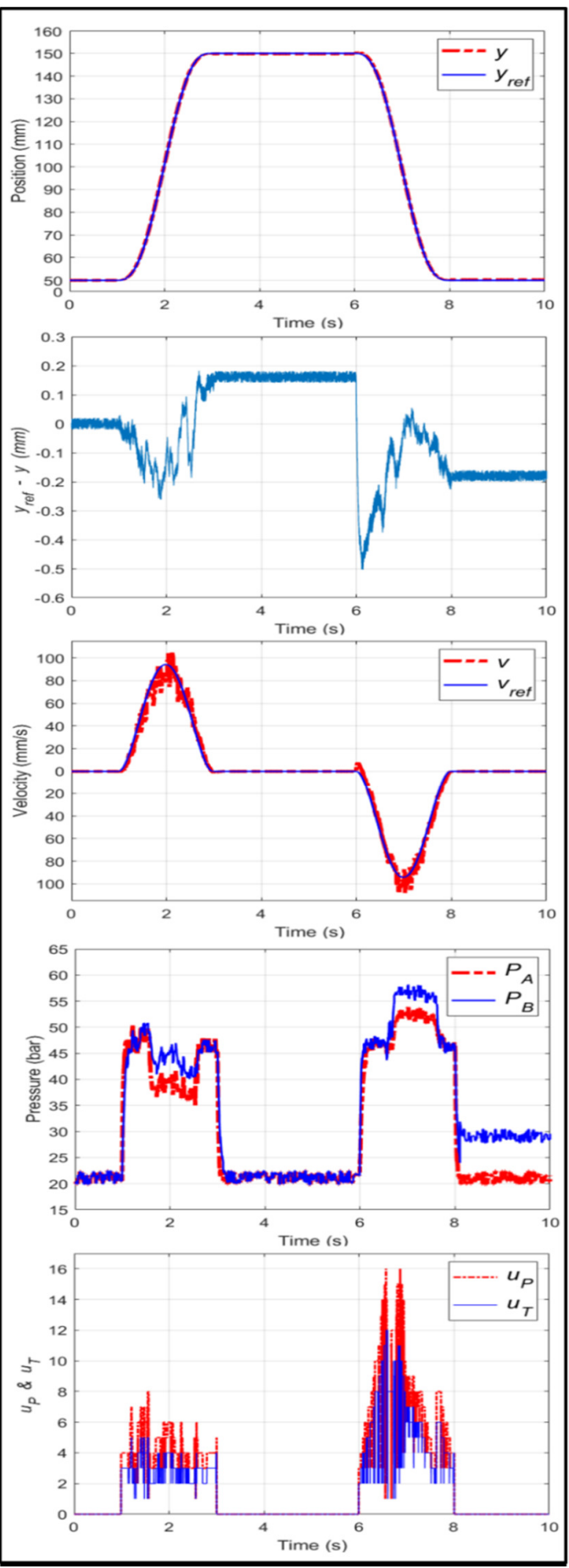

Fig. 7. $\quad 100 \mathrm{~mm}$ displacement tracking results.

The $50 \mathrm{~mm}$ tracking response error can also be tolerated by changing orifices. Also, by increasing valve number and using smaller flow rate valves, 25, 50, and $100 \mathrm{~mm}$ tracking responses can give good results. On the other hand, the studied valve uses a vertically placed cam, and this results in a wider valve manifold with more valves. Cam operated valves cannot be placed crosswise like solenoid operated digital hydraulic valves. It can be concluded that the valve can present great 
performance for bigger systems due to manufacturing limits. An essential result is achieved because cheaper components than the solenoid-operated digital hydraulic valves are used.

It is possible to obtain smoother movement with smaller flow rate of valves. This comes with a larger volume, but with a smaller price.

In summary, our first digital hydraulic valve is not as superior as the previously studied digital hydraulic valves due to the used cam and servo motor, but it can be improved with a smaller design and more valves while it has already showed its potential with inexpensive components.

\section{ACKNOWLEDGMENT}

This study was funded by the Scientific and Technological Research Council of Turkey (TUBITAK) ARDEB 1002 Grant No 218M256.

\section{REFERENCES}

[1] K. A. Venkataraman, K. Kanthavel, and B. N. Kumar, "Investigations of Response Time Parameters of a Pneumatic 3/2 Direct Acting Solenoid Valve Under Various Working Pressure Conditions," Engineering, Technology \& Applied Science Research, vol. 3, no. 4, pp. 502-505, Aug. 2013, https://doi.org/10.48084/etasr.360.

[2] A. Gupta, N. Bokde, D. Marathe, and K. Kulat, "Leakage Reduction in Water Distribution Systems with Efficient Placement and Control of Pressure Reducing Valves Using Soft Computing Techniques," Engineering, Technology \& Applied Science Research, vol. 7, no. 2, pp. 1528-1534, Apr. 2017, https://doi.org/10.48084/etasr.1032.

[3] J. Mattila and T. Virvalo, "Energy-efficient motion control of a hydraulic manipulator," in Millennium Conference. IEEE International Conference on Robotics and Automation. Symposia Proceedings, San Francisco, CA, USA, Apr. 2000, vol. 3, pp. 3000-3006 vol.3, https://doi.org/10.1109/ROBOT.2000.846483.

[4] Bin B. Yao and S. Liu, "Energy-saving control of hydraulic systems with novel programmable valves," in 4th World Congress on Intelligent Control and Automation, Shanghai, China, Jun. 2002, vol. 4, pp. 3219 3223 vol.4, https://doi.org/10.1109/WCICA.2002.1020129.

[5] M. Linjama, K. T. Koskinen, and M. Vilenius, "Accurate Trajectory Tracking Control of Water Hydraulic Cylinder with Non-Ideal on/off Valves," International Journal of Fluid Power, vol. 4, no. 1, pp. 7-16, Jan. 2003, https://doi.org/10.1080/14399776.2003.10781151.

[6] M. Linjama, "Digital fluid power-state of the art," in 12th Scandinavian International Conference on Fluid Power, Tampere, Finland, May 2011.

[7] M. Linjama, J. Seppala, J. Mattila, and M. Vilenius, "Comparison of digital hydraulic and traditional servo system in demanding water hydraulic tracking control," in Fluid Power and Motion Control, 2008, pp. 393-403.

[8] S. Liu and B. Yao, "Energy-Saving Control of Single-Rod Hydraulic Cylinders with Programmable Valves and Improved Working Mode Selection," in SAE Transactions, vol. 111, 2002, pp. 51-61.

[9] H. Hu and Q. Zhang, "Realization of Programmable Control using a Set of Individually Controlled Electrohydraulic Valves," International Journal of Fluid Power, vol. 3, no. 2, pp. 29-34, Jan. 2002, https://doi.org/10.1080/14399776.2002.10781135.

[10] A. Shenouda and W. J. Book, "Selection of Operating Modes of a MultiFunctional Hydraulic Device," in International Mechanical Engineering Congress and Exposition, Orlando, FL, USA, Nov. 2005, pp. 99-109, https://doi.org/10.1115/IMECE2005-81687.

[11] M. Linjama, A. Laamanen, and M. Vilenius, "Is it time for digital hydraulics?," in The Eight Scandinavian International Conference on Fluid Power, Tampere, Finland, May 2003, pp. 347-366.

[12] L. Siivonen, M. Linjama, and M. Vilenius, "Analysis of fault tolerance of digital hydraulic valve system," in Power Transmission and Motion Control, 2005, pp. 133-146.
[13] A. Laamanen, L. Siivonen, M. Linjama, and M. Vilenius, "Digital flow control unit - An alternative for a proportional valve?," in Bath Workshop on Power Transmission and Motion Control, 2004, pp. 297 308.

[14] M. Linjama and M. Vilenius, "Energy-efficient motion control of a digital hydraulic joint actuator," in 6th JFPS International Symposium on Fluid Power, Tsukuba, Japani, Nov. 2005, vol. 2005, pp. 640-645, https://doi.org/10.5739/isfp.2005.640.

[15] M. Linjama, M. Huova, O. Karhu, and K. Huhtala, "High-Performance Digital Hydraulic Tracking Control of a Mobile Boom Mockup," in 10th International Fluid Power Conference, Dresden, Germany, Mar. 2016, pp. $37-48$.

[16] M. Linjama, H.-P. Vihtanen, A. Sipola, and M. Vilenius, "Secondary controlled multi-chamber hydraulic cylinder," in 11th Scandinavian International Conference on Fluid Power, Linkoping, Sweden, Jun. 2009.

[17] H. Berg and M. Ivantysynova, "Design and testing of a robust linear controller for secondary controlled hydraulic drive," Proceedings of the Institution of Mechanical Engineers, Part I: Journal of Systems and Control Engineering, vol. 213, no. 5, pp. 375-386, Aug. 1999, https://doi.org/10.1243/0959651991540223.

[18] M. Huova, A. Laamanen, and M. Linjama, "Energy Efficiency of ThreeChamber Cylinder with Digital Valve System," International Journal of Fluid Power, vol. 11, no. 3, pp. 15-22, Jan. 2010, https://doi.org/ 10.1080/14399776.2010.10781011.

[19] M. Huova and M. Linjama, "Energy efficient digital hydraulic valve control utilizing pressurized tank line," in Proceedings of the 8th International Fluid Power Conference, Dresden, Germany, Mar. 2012, pp. 111-122.

[20] M. Paloniitty and M. Linjama, "High-linear digital hydraulic valve control by an equal coded valve system and novel switching schemes," Proceedings of the Institution of Mechanical Engineers, Part I: Journal of Systems and Control Engineering, vol. 232, no. 3, pp. 258-269, Mar. 2018, https://doi.org/10.1177/0959651817750519.

[21] M. Linjama and M. Vilenius, "Improved Digital Hydraulic Tracking Control of Water Hydraulic Cylinder Drive," International Journal of Fluid Power, vol. 6, no. 1, pp. 29-39, Jan. 2005, https://doi.org/10.1080/ 14399776.2005.10781209.

[22] T. Lantela and M. Pietola, "High-flow rate miniature digital valve system," International Journal of Fluid Power, vol. 18, no. 3, pp. 188195, Sep. 2017, https://doi.org/10.1080/14399776.2017.1358025.

[23] M. Linjama, M. Paloniitty, L. Tiainen, and K. Huhtala, "Mechatronic Design of Digital Hydraulic Micro Valve Package," Procedia Engineering, vol. 106, pp. 97-107, Jan. 2015, https://doi.org/10.1016/ j.proeng.2015.06.013.

[24] S. Chekurov and T. Lantela, "Selective Laser Melted Digital Hydraulic Valve System," 3D Printing and Additive Manufacturing, vol. 4, no. 4, pp. 215-221, Dec. 2017, https://doi.org/10.1089/3dp.2017.0014.

[25] M. Paloniitty, M. Linjama, and K. Huhtala, "Equal Coded Digital Hydraulic Valve System - Improving Tracking Control with Pulse Frequency Modulation," Procedia Engineering, vol. 106, pp. 83-91, Jan. 2015, https://doi.org/10.1016/j.proeng.2015.06.011.

[26] S. Babesse, "Design of Two Optimized Controllers of a Hydraulic Actuator Semi-Active Suspension: A Comparison Study," Engineering, Technology \& Applied Science Research, vol. 9, no. 4, pp. 4561-4565, Aug. 2019, https://doi.org/10.48084/etasr.2836. 